\title{
VALUE OF EFFECTIVE FEEDBACK TO CANDIDATES LEADS TO IMPROVING THE LEARNING GOAL
}

\author{
Ann Toler Hilliard, \& Renee Foose \\ Dr., Department of Educational Studies and Leadership, Bowie State University (U.S.A.)
}

\begin{abstract}
Feedback is designed to respond to candidates' work in an online environment and/or face-to-face environment. University faculty members can give feedback to candidates in many ways such as oral and written responses with attached notes for improvement. For the purpose of clarity and accountability, feedback in written form is preferred in most academic settings. In order for candidates to know how they are performing, feedback is necessary. Using a qualitative study, these researchers provided a perspective of what graduate candidates thought about the feedback that was rendered to them by faculty and faculty members gave their own views regarding the rendering of effective feedback being given to graduate candidates. Emphases for this study included best practices, ways to give online and off-line feedback timelier. The major finding suggested that there was a disconnect between what candidates and faculty members thought about how feedback was given. In this study, the findings further suggested that faculty members felt that candidates received feedback very well and timely feedback on work presented. However, candidates felt overall that feedback was not done timely enough so that their work could be improved upon in the class now, not after candidates leave the class. In conclusion, faculty members must do a better job giving helpful, relevant feedback and must give feedback timelier were the common words expressed by candidates.
\end{abstract}

Keywords: Effective and timely feedback, perspectives, learning outcomes.

\section{Introduction}

Feedback is an invaluable respond to candidates' work at the university. Faculty members need to provide candidates with feedback to explain their grades and the improvement of a task performed but more importantly faculty members need to help candidates use feedback to promote their learning throughout their time at the university. Feedback given by faculty members can help candidates recognize the value of feedback and how feedback can assist candidates in being more productive on current and later coursework assignments for productive learning. The feedback from faculty members can help clarify requirements and expectations for candidates' coursework and to discuss how each assignment connects to candidates' learning experiences. The feedback to candidates can help faculty members too, to realize how to gauge the level of instructional services to candidates in an improved manner. It is important to note the question is what works best in the teaching and learning environment and the importance of constructive feedback being given to students (Atherton, 2011).

In order for candidates to know or to receive some sense of the quality of their work, feedback is necessary. It is important to give candidate feedback on work performance, faculty should frequently give formative assessment feedback to candidate so that candidates have the opportunity to improve their performance. Formative feedback techniques include many interactive classroom activities, homework and surveys. Formative would also be weekly or bi-weekly assessment of candidates' performance. By way of contrast, summative feedback typically falls at the end of a topic or semester. It provides an evaluation of how much a student and the class has learned and is often connected to a grade for the course. However, effective feedback formative or summative by faculty members should provide candidates with specific information about their performance based on a prescribed rubric for the course and activities within the course (Shute, 2008).

\section{Best practices for feedback}

It is important for faculty members to stay focused on why the feedback is being given, just in case the candidate has questions about the feedback. Always be professional in selecting words for 
feedback to candidates. The guiding principle for feedback should be candidate-centered and should be objectively given in a professional manner and timely (Cowan, 2003). All feedback to candidates should focus on the work completed or ongoing work on a project engaged by candidate and the academic needs of the candidate. If the quality of the work needs improving, give specific suggestions how candidates may wish to rewrite or clarify their work. It is important too, to give all feedback on candidates' work that would help candidates to move closer to the target expectation. Feedback should be descriptive not negative or judgmental by faculty members and faculty could look at what feedback appears to work best for different candidates' needs (Atherton, 2011).

\subsection{Statement of the problem}

For this study, graduate candidates have expressed that faculty members overall do not give feedback to them in a timely manner in order for candidates to improve their learning experiences in various courses. A critical review has shown that 40-60 percent of doctoral students do not finish programs of study, because they have not received needed advisement, feedback and general support from faculty members concluded that high attrition of doctoral students results in loss of time, talent, and finances for the university, the faculty and doctoral candidate themselves. Effective feedback and advisement have contributed to candidates staying in college; therefore, support to candidates in very important (Orrell, 2006).

\subsection{Purpose of the study}

The purpose of this qualitative study is to provide a perspective of what graduate candidates think about the feedback that is rendered to them by faculty and what are the views of faculty member regarding the rendering of effective feedback being given to graduate candidates. This study is to make a true awareness to faculty that there is a need for faculty members to do a better job supporting candidates' needs by giving meaningful feedback timelier.

\subsection{The framework and process for giving feedback practice}

A feedback framework seeks to demystify the process of reviewing performance in the workplace and student learning environment. Feedback is a common evaluative response to candidates' work for the purpose of improving the quality of the work performed by candidates. Feedback on assessments is an integral feature of effective and efficient teaching and learning and can be one of the most powerful ways in which to enhance and strengthen candidate or student learning in a helpful manner (Cain, 2019). Feedback enables learning by providing information that can be used to improve and enhance future performance. The purpose of a typical framework is to establish a series of protocols for feedback which set expectations for feedback on assessment as part of the implementation of the learning, teaching and assessment strategy such as being specific, prescriptive, positive and professional. The intention is not to inhibit the academic success of courses by micro-management or over simplification, but to provide a broad framework to encourage sound practices and guidelines for staff and students.

\subsection{Research questions}

This study was led by the use of qualitative inquiry narrative questions as follows:

Candidates: 1). Do you feel that the feedback given to you improved your skills and knowledge? 2). Do you feel that the courses taken and the ways that these courses were taught were aligned with educational leadership practices at the building or district level? 3). Do you feel that online or a hybrid platform was an effective learning experience instructionally speaking? 4). Was feedback given to you in a timely manner? 5). Do you feel comfortable asking faculty members for help, when you have a need?

Faculty: 1). How would you rate your different types of communicative feedbacks given to candidates? 2). What types of platforms have you used to give feedback to candidates? 3). Do you give positive and unfavorable feedback to candidates in written form? 4). Do you enjoy using different types of platforms to delivery instructional services to students? 5). Do you submit feedback to candidates in a timely manner?

\subsection{Limitation of this study}

This study included only one comprehensive university, $n=29$ graduate candidates and $n=6$ graduate faculty in the leadership department. 


\subsection{Assumptions}

It is assumed that participants in this study have provided honest responses, because their identification (name and university) will be concealed and their confidentiality preserved (Simon \& Goes, 2013).

\subsection{Significant of this study}

This study is significant because it gives candidates clear guidance as to how to improve their learning when giving feedback in a timely manner from faculty members. Feedback can also improve a student's confidence, self-awareness and enthusiasm for learning at all ages. Effective feedback can help candidates to seek post-graduate studies, to present work in a comfort manner at conferences at the state and national level. The university faculty members can aid the transition to higher education opportunities to support student retention and give students the desirability or motivation to pursue, for example, a terminal degree for knowledge, skills and career advancement.

\subsection{Literature review}

Historically, the quality of education that graduate students receive is greatly enhanced if candidates receive appropriate feedback in their various classes. Candidates may receive different types of feedback in courses from various faculty members; however, feedback should be given timely and for the purpose of improving candidates' learning experiences. There are several types of feedback such as: informal, formal, formative, summative, peer, self and constructive. It is important to know the effectiveness of the different types of feedback (Poulas \& Mahony, 2007). Each has its place in enhancing and maximizing candidates' learning experiences, thus where possible, courses could provide opportunities for a range of feedback types. There could be a combination of feedback types as mentioned. In this study, many faculty members stated that they would sometime encourage self and peer evaluation in various courses in order to give candidates time to review and reflect on their own performance (Carless, 2006).

\section{Giving online feedback}

Today, the use of e-feedback can provide faculty members with the opportunity to review candidates' work online in a timely manner. It is the belief by some researchers that e-feedback is very effective, because faculty members can quickly review candidates' work by using email feedback, audio, blackboard platform, screen-casts feedback and also by using a blended learning approach for feedback. Using online feedback has the following advantages: software is in place for use by faculty members and computers could be programmed to give ongoing feedback tirelessly and serve as an interactive tool for candidates' use. Candidates can focus on and digest comments at a time of their choosing in the absence of their peers when e-feedback is given (Piccinin, 2003). Also, feedback is more legible than written comments by hand. Electronic feedback can help candidates to refer to cumulative comments as they move through the curriculum. Candidates may find greater engagement with electronic feedback. There are also two major types of effective feedback such as elaboration and verification. Elaboration feedback gives the candidate relevant cues toward correcting the task assignment and verification is given if the answer is correct or incorrect as an immediate response (Hummell, 2006).

\section{Methodology}

This qualitative inquiry narrative study sought to gain a perspective from graduate candidates and faculty members on the value of effective feedback. The research for this study involved the use of survey and one-on-one interviews using open-ended questions.

\subsection{Research design}

This study used a qualitative narrative approach by submitting electronic brief survey with graduate candidates and conduct an interview face-to-face with faculty members who taught graduate courses. Also, conducted in-depth interviews, read documents, and look for themes; in other words, how does an individual story illustrate the larger life influences that created it (Braun \& Clark, 2006). Often interviews are conducted over weeks, months, or even years, but the final narrative doesn't need to be in chronological order. Rather it can be presented as a story (or narrative) with themes, and can reconcile conflicting stories and highlight tensions and challenges which can be opportunities for innovation. The qualitative narrative approach for this research, because the researchers looked at and recorded individual experiences. 


\subsection{Participants}

This research used a very small sample $n=29$ doctorate candidates/graduated participants and $\mathrm{n}=6$ graduate faculty members whom all gave their perceptive on effective feedback. This qualitative inquiry narrative study only focused on graduate candidate and graduate faculty members in the Department of Educational Studies and Leadership at a comprehensive university in mid-Western location of the United States. The researchers used data survey questions for each group of participants.

\subsection{Instrumentation}

The survey information and questions were taken from the Post-training Evaluation Survey form, Published on: 28 Jan 2019 by Aris Apostolopoulos, CIMS Survey, 2019. These survey questions came from sections of IMS that included course, structure, delivery, design and outcomes.

\subsection{Reliability and validity}

Reliability for qualitative research lies with consistency. A margin of variability for results is tolerated in qualitative research provided the methodology and epistemological logistics consistently yield data that are ontologically similar but may differ in richness and ambience within similar dimensions. Validity in qualitative research means "appropriateness" of the tools, processes, and data. Whether the research question is valid for the desired outcome, the choice of methodology is appropriate for answering the research question, the design is valid for the methodology, the sampling and data analysis is appropriate, and finally the results and conclusions are valid for the sample and context (Bansal \& Corley, 2004).

\subsection{Collection of data}

For this qualitative study data were collected from $n=29$ students and $n=6$ faculty members participated in this study from January 10 thru 25, 2019. Data collection for this qualitative study comes in the form of participants' observations and generalizations, with conclusions drawn from these observations.

A total of 40 candidates were surveyed electronically initially, but only 29 electronic responses were returned and all 6 faculty members participated fully in this study. The participating faculty members were surveyed before classes started during the pm. Interviewing process was audio-taped and transcribed verbatim between 40 minutes and a total of 3 hours among the 6 faculty members.

The six (6) faculty participants for this study were faulty members who taught graduate courses full-time at the comprehensive university located in the mid-Atlantic region of the United States. The purpose of this study was to hear the voices of faculty and their feedback experiences and perspectives of the voices of graduate candidates. The faculty participants were seasoned individuals in graduate degree programs in the department of educational studies and leadership and who had taught graduate courses for seven to eleven years.

The researchers documented codes and linkages based on thematic analysis provided a rich and detailed account for formal data analysis (Braun \& Clarke, 2006). The analyses of this study were based on an inductive approach that focused on emergent themes that were derived from the surveys and interviews. The survey responses and interview transcripts were analyzed using coding categories, or common themes as referred by Bogdan and Biklen (2007) as, "words and phrases developed to be used to sort and analyze qualitative data" (Bogdan and Biklen, 2008, p. 271).

\subsection{Results and findings}

\section{Findings from Common Themes Derived from Students}

1. Confidence Building and Motivation: When feedback is given in helpful in a professional manner I am motivated to learn more and the feedback could help me when taking future graduate courses.

2. Proofreading and Assessing my Own Work: Will be motivated to learn and will be confident with new or challenging experiences.

3. Acceptance of Constructive Feedback: More open-minded about feedback given if it is useful.

4. Timely Feedback: Too many faculty members do not give feed timely and frequently enough in order for candidates to improve in that specific course.

5. Technology Use: Perhaps more faculty member should use more types of technology to give feedback timelier to students.

Findings from Common Themes Derived from Faculty

1. Feedback Rating Overall: Feedback is given to candidates frequently to improve their writing skills. 
2. Delivery System of Feedback: Give feedback when candidates are assessed mid-term and the end of the semester.

3. Communication: Give feedback on papers by writing helpful comments on candidates' paper.

4. Timely Feedback: Yes, I give feedback timely to candidates.

5. Online Platform: I may use sometimes a form of online ways to give candidate feedback.

Findings further suggest, that faculty members felt that candidates received feedback very good and timely feedback on work presented. However, candidates felt overall that feedback is not done timely enough so that their work could be improved upon in the class not after they leave the class. Also candidates felt, if faculty members used more technology platforms, faculty members could perhaps respond more timely with needed feedback to candidates.

\section{Conclusion}

Measuring the quality or effectiveness of feedback is important. It is essential to look at some known qualities of effective feedback based on research. Different references or comments may give various types of feedback. However, the effectiveness of the most common feedback can occur when the behavior of candidates change based on the intention of feedback from faculty members. The overall intent of feedback is to assist candidates with improving the quality of their work. Feedback should be given to encourage and motivate candidates, too. It is hoped that this experience would help to move candidates toward continuous progress related to their educational learning goals (Shute, 2008). However, faculty members can best serve candidates and students by providing clearly written feedback electronically and/or handwritten in a timely manner in order to help candidates and students to improve their performance (Kulhavy, 2009).

\section{References}

Apostolopoules, A. (2018). Narratively: Human Stories, Boldly Told. Support our Storytelling During These Challenging Times. Creative Narratively, Inc.

Atherton, J. S. (2011) Teaching and Learning; What works best [On-line: UK] retrieved 27\ March 2013 from http://www.learningandteaching.info/teaching/what_works.htm

Bansal, P., \& Corley, K. (2011). From the editors the coming of age for qualitative research: Embracing the diversity of qualitative methods. Academy of Management Journal, 54(2), 233-237. https://doi.org/10.5465/AMJ.2011.60262792

Bogdan, R.C., \& Biklen, S.K. (2007). Qualitative Research for Education: An Introduction to Theory and Methods. 5th Edition, Allyn \& Bacon, Boston.

Braun, V., \& Clarke, V. (2006). Using thematic analysis in psychology. Qualitative Research in Psychology, 3, 77-101.

Cain, L. (2019). How to Give Effective Performance Feedback: Frameworks and Best Practices. Openview Venture Partners.

Carless, D. (2006). Differing perceptions in the feedback process. Studies in Higher Education, 31(2), 219-322.

Cowan, J. (2003). Assessment for learning: Giving timely and effective feedback. Exchange 4:21-22.

Hummell, H. (2006). Feedback model to support designers of blended-learning courses. International Review of Research in Open and Distance Learning, 7 (3), 1-16.

Kulhavy, S. (2009). Feedback in written instruction. Review of Educational Research, 47.

Orrell, J., (2006). Feedback on learning achievement: rhetoric and reality. Teaching in Higher Education Vol. 11, No. 4, October 2006, pp. 441-456.

Piccinin, S. J., (2003). Feedback: Key to Learning. Halifax, N.S. Society for Teaching and Learning in Higher Education.

Poulas, A., \& Mahony, J. (2007). Effectiveness of feedback: The students' perspective. Assessment and Evaluation in Higher Education 33, no. 2: 143-54.

Schute VJ. (2008). Focus on Formative Feedback. Review of Educational Research March 78:153-189.

Simon, M. K., \& Goes, J. (2013). Dissertation and scholarly research: Recipes for success. Seattle WA, Dissertation Success, LLC.

Wolsey, T., (2008). Efficacy of instructor feedback on written work in an online program. International Journal on E-Learning, 7 (2), 311-329. 